\title{
A 3D IN VITRO BONE ORGAN MODEL USING HUMAN PROGENITOR CELLS
}

\author{
Adam Papadimitropoulos ${ }^{1}$, Arnaud Scherberich ${ }^{1}$, Sinan Güven ${ }^{1}$, Naseem Theilgaard ${ }^{3}$, Hendrikus J.A. Crooijmans ${ }^{2}$, \\ Francesco Santini ${ }^{2}$, Klaus Scheffler ${ }^{2}$, Alberta Zallone ${ }^{4}$ and Ivan Martin ${ }^{1, *}$ \\ ${ }^{1}$ Departments of Surgery and of Biomedicine, University Hospital Basel, Basel, Switzerland \\ ${ }^{2}$ Division of Radiological Physics, University Hospital Basel, Basel, Switzerland \\ ${ }^{3}$ Danish Technological Institute, Taastrup, Denmark \\ ${ }^{4}$ University of Bari, Bari, Italy
}

\begin{abstract}
Three-dimensional (3D) organotypic culture models based on human cells may reduce the use of complex and costly animal models, while gaining clinical relevance. This study aimed at developing a 3D osteoblastic-osteoclasticendothelial cell co-culture system, as an in vitro model to mimic the process of bone turnover. Osteoprogenitor and endothelial lineage cells were isolated from the stromal vascular fraction (SVF) of human adipose tissue, whereas CD14+ osteoclast progenitors were derived from human peripheral blood. Cells were co-cultured within 3D porous ceramic scaffolds using a perfusion-based bioreactor device, in the presence of typical osteoclastogenic factors. After 3 weeks, the scaffolds contained cells with endothelial (2.0 $\pm 0.3 \%)$, pre/osteoclastic $(14.0 \pm 1.4 \%)$ and mesenchymal/ osteoblastic $(44.0 \pm 8.4 \%)$ phenotypes, along with tartrateresistant acid phosphatase-positive $\left(\mathrm{TRAP}^{+}\right)$osteoclastic cells in contact with deposited bone-like matrix. Supernatant analysis demonstrated sustained matrix deposition (by C-terminus procollagen-I propeptides), resorption (by $\mathrm{N}$-terminus collagen-I telopeptides and phosphate levels) and osteoclastic activity (by TRAP-5b) only when SVF and $\mathrm{CD} 14+$ cells were co-cultured. Scanning electron microscopy and magnetic resonance imaging confirmed the pattern of matrix deposition and resorption. The effectiveness of Vitamin D in replacing osteoclastogenic factors indicated a functional osteoblast-osteoclast coupling in the system. The formation of human-origin bonelike tissue, blood vessels and osteoclasts upon ectopic implantation validated the functionality of the developed cell types. The 3D co-culture system and the associated non-invasive analytical tools can be used as an advanced model to capture some aspects of the functional coupling of bone-like matrix deposition and resorption and could be exploited toward the engineering of multi-functional bone substitute implants.
\end{abstract}

Keywords: Perfusion bioreactor, human stem cellspopulation regulation, tissue engineering / regenerative medicine, bone remodelling, non invasive tools, multi-cell co-culture.

\section{*Address for correspondence: \\ Ivan Martin \\ Departments of Surgery and of Biomedicine \\ University Hospital Basel, \\ Hebelstrasse 20 \\ CH-4031 Basel, Switzerland}

Telephone Number: +41612652384

FAX Number: +41 612653990

E-mail: Martini@uhbs.ch

\section{Introduction}

The structure, function and remodelling of bone as an organ is dynamically regulated by complex three-dimensional (3D) interactions among various cell types, including those of the osteoblastic, osteoclastic, endothelial and haematopoietic lineages (Parfitt, 1994; Collin-Osdoby, 1994; Parfitt, 2000; Pogoda et al., 2005; Matsuo and Irie, 2008; Tortelli and Cancedda, 2009). In order to investigate the mechanisms underlying physiological and pathological cellular processes in bone, animal models are often considered not satisfactory. In fact, in addition to the high costs and large degree of systemic complexity, they often do not faithfully recapitulate the biological programs specific of the human species and fail to be predictive of a clinical outcome (Pearce et al., 2007). Ex vivo cultured bone explants have been proposed for studies on bone cell biology (Meghji et al., 1997). However, long term cultures of such specimens suffer from inadequate supply of nutrients and oxygen and typically result in necrosis of the major part of the organ. Recently, the use of bioreactor devices applying mechanical loading and medium recirculation was shown to favour cell viability and prolong culture time of bone explants (David et al., 2008; Simpson et al., 2009). Nevertheless, these studies indicate the need of further improvements in mass transfer rates, as well as the limits of large inter- and intra-donor variability among different bone explant preparations.

The alternative co-culture of osteoblastic and osteoclastic lineage cells on two-dimensional (2D) plastic or mineralised substrates has been instrumental to a number of important advances in the field. Nevertheless, the approach fails to capture the 3D spatial interactions typical of a living bone organ, and was reported to possibly lead to erroneous observations and conclusions (Hutmacher $e t$ al., 2010). So far, only a few studies have addressed the possibility to establish a $3 \mathrm{D}$ co-culture model for bone cells using mineralised porous scaffolds as templates. The systems, though established for animal-origin cells, have demonstrated the feasibility to reproduce both the formation of an organised bone-like matrix (Tortelli et al., 2009), and a cell-mediated substrate degradation (Nakagawa et al., 2004; Domaschke et al., 2006; Tortelli and Cancedda, 2009). A recent study morphologically validated the extension of previous models to human cells cultured within composite scaffolds, with the perspective to test the performance of biomaterials in vitro (Heinemann et al., 2011). Collectively, these studies warrant the further development of 3D models of bone tissue remodelling using human-derived cells, with direct monitoring of the relevant metabolic parameters and possibly reaching a higher level of fidelity to the bone 
organ. In this regard, the additional presence of endothelial cells could play an important role, due to their modulatory activity on osteoblastic/osteoclastic cells (Zaidi et al., 1993; Parfitt, 2000) and considering that bone development and remodelling is closely regulated by the vascular system (Hauge et al., 2001).

Recently, we have established a co-culture model of human osteoblast and endothelial lineage cells by seeding and culturing cells freshly isolated from the stromal vascular fraction (SVF) of adipose tissue within porous 3D ceramic scaffolds. The system, which critically relies on the use of a perfusion-based bioreactor device (Wendt et al., 2003), was reported to generate 3D constructs that, upon implantation into nude mice, were capable to generate bone tissue and fully functional blood vessels, both of human origin (Scherberich et al., 2007).

In the present study, we aimed at the further development of the model as a bone organotypic culture by introducing an osteoclastic cell source, namely human peripheral blood-derived monocytes (Komano et al., 2006; Sorensen et al., 2007). The multi-cell co-culture system was assessed for the presence and functionality of its different cellular components. Moreover, non-invasive techniques were established to monitor bone-like matrix deposition and resorption in vitro and to validate the regulation of such processes by osteoclastogenic and osteotropic factors.

\section{Materials and Methods}

\section{Cell isolation}

Human adipose tissue-derived stromal vascular fraction (SVF) cells

Subcutaneous adipose tissue in the form of lipoaspirates was obtained from the inner and/or outer thighs of healthy donors, after informed consent and following protocol approval by the local ethical committee. The tissue was digested in $0.075 \%(\mathrm{w} / \mathrm{v})$ collagenase type II (Worthington, Lakewood, NJ, USA) for $45 \mathrm{~min}$ at $37^{\circ} \mathrm{C}$ on an orbital shaker. The cell suspension was thereafter centrifuged at $400 \mathrm{~g}$ for $10 \mathrm{~min}$, and the resulting pellet was washed once with phosphate-buffered saline (PBS), resuspended in $\alpha$-Modified Eagle's Medium ( $\alpha$-MEM) containing 10\% of foetal bovine serum (all from Gibco, Invitrogen, Life Technologies, Carlsbad, CA, USA), and passed through a $100 \mu \mathrm{m}$ strainer (BD Biosciences, Franklin Lakes, NJ, USA). Red blood cells were then lysed by incubation for 5 min with a buffer containing $150 \mathrm{mM}$ ammonium chloride, $1.0 \mathrm{mM}$ potassium bicarbonate and $0.1 \mathrm{mM} \mathrm{Na}-$ EDTA. After centrifugation and washing in PBS, the SVF cells were suspended in $\alpha$-MEM supplemented with $10 \%$ FBS, 10 mM HEPES buffer, $1 \mathrm{mM}$ sodium pyruvate, 100 $\mathrm{U} / \mathrm{ml}$ penicillin and $100 \mu \mathrm{g} / \mathrm{mL}$ streptomycin (complete medium, all from Gibco, Invitrogen) and counted by using a Neubauer chamber.

\section{Peripheral blood derived CD14+ monocytes}

Mononuclear cells were isolated from human peripheral blood buffy coats from healthy donors (different from SVF cells donors) by gradient centrifugation (Ficoll, Histopaque 1077, Sigma-Aldrich, St. Louis, MO, USA). Subsequently, CD14+ monocytes were sorted using anti-CD14-coated magnetic beads (Miltenyi Biotec, Auburn, CA, USA), according to the manufacturer's instructions.

\section{Cell cultures}

Establishment of the 3D co-culture system

3D co-cultures were established using a perfusion bioreactor system, previously developed for cell seeding and cultivation into 3D scaffolds (Wendt et al., 2003) following a two-phase strategy, as shown in Fig. 1. In the first phase, $2 \times 10^{6}$ freshly isolated SVF resuspended in 8 $\mathrm{mL}$ of complete medium were perfused through $8 \mathrm{~mm}$ diameter, $4 \mathrm{~mm}$ thick disks of porous hydroxyapatite/ beta-tricalcium phosphate (HA/ $\beta$ TCP, 70/30 w/w, 80\% porosity) scaffolds, produced by the Danish Technological Institute (DTI, Taarstrup, Denmark) using powders from Fin-Ceramica (Fin-Ceramica Faenza S.p.A, Faenza, Italy). The composition of the ceramic scaffold was selected in order to allow osteoclast resorption (Yamada et al., 1997; Detsch et al., 2008; Komlev et al., 2010). The SVF cell suspension was perfused for 5 days at a superficial velocity of $400 \mu \mathrm{m} / \mathrm{s}$, previously demonstrated to result in efficient and uniform cell seeding. In the second phase, $4 \times 10^{6}$ freshly isolated CD14+ monocytes were introduced into each SVFpopulated scaffold using the same perfusion bioreactor system for further 4 days at a superficial velocity of 400 $\mu \mathrm{m} / \mathrm{s}$ in the presence of complete medium supplemented with macrophage colony-stimulating factor (MCSF, $25 \mathrm{ng}$ / $\mathrm{mL}, \mathrm{R} \& \mathrm{D}$ systems, Minneapolis, MN, USA), to promote adhesion and proliferation of monocytes. Thereafter, the culture medium was changed into complete medium supplemented with MCSF $(25 \mathrm{ng} / \mathrm{mL})$ and receptor activator for $\kappa \mathrm{B}$ factor ligand (RANK-ligand, $50 \mathrm{ng}$ / $\mathrm{mL}, \mathrm{R} \& \mathrm{D}$ systems) to promote osteoclast differentiation (osteoclastogenic medium) and refreshed every 4 days for an additional period of 12 days at a superficial velocity of $100 \mu \mathrm{m} / \mathrm{s}$ (the total culture time for phases 1 and 2 was 21 days). The so established co-culture will be hereafter referred to as SVF/CD14+. 3D cultures using only SVF (21 day culture) or only CD14+ (17 day culture) cells were also performed according to the protocol described above and served as controls. For each experimental group, cellfree scaffolds were similarly cultured to establish baseline levels of soluble factors in the supernatant.

\section{In vitro functionality of the $3 D$ co-culture system}

In some experiments, the culture protocol described above was adapted in order to stimulate an osteogenic commitment of the freshly harvested SVF population and demonstrate the self-regulated osteoclastogenic capacity of the system. For this set of experiments, the duration of the first culture phase was extended to 7 days using complete medium further supplemented with $5 \mathrm{ng} /$ $\mathrm{mL}$ fibroblast growth factor-2 (R\&D Systems), $10 \mathrm{nM}$ dexamethasone, and $0.1 \mathrm{mM}$ L-ascorbic acid-2-phosphate (both from Sigma-Aldrich) (Scherberich et al., 2007). During the second culture phase, medium consisted of complete medium further supplemented with $10 \mathrm{nM}$ $1 \alpha, 25$-Dihydroxyvitamin $\mathrm{D}_{3}$ (VitD ${ }_{3}$, Sigma-Aldrich). $3 \mathrm{D}$ cultures using complete medium or osteoclastogenic medium were also performed and served as controls. For each experimental group, cell-free scaffolds were also 


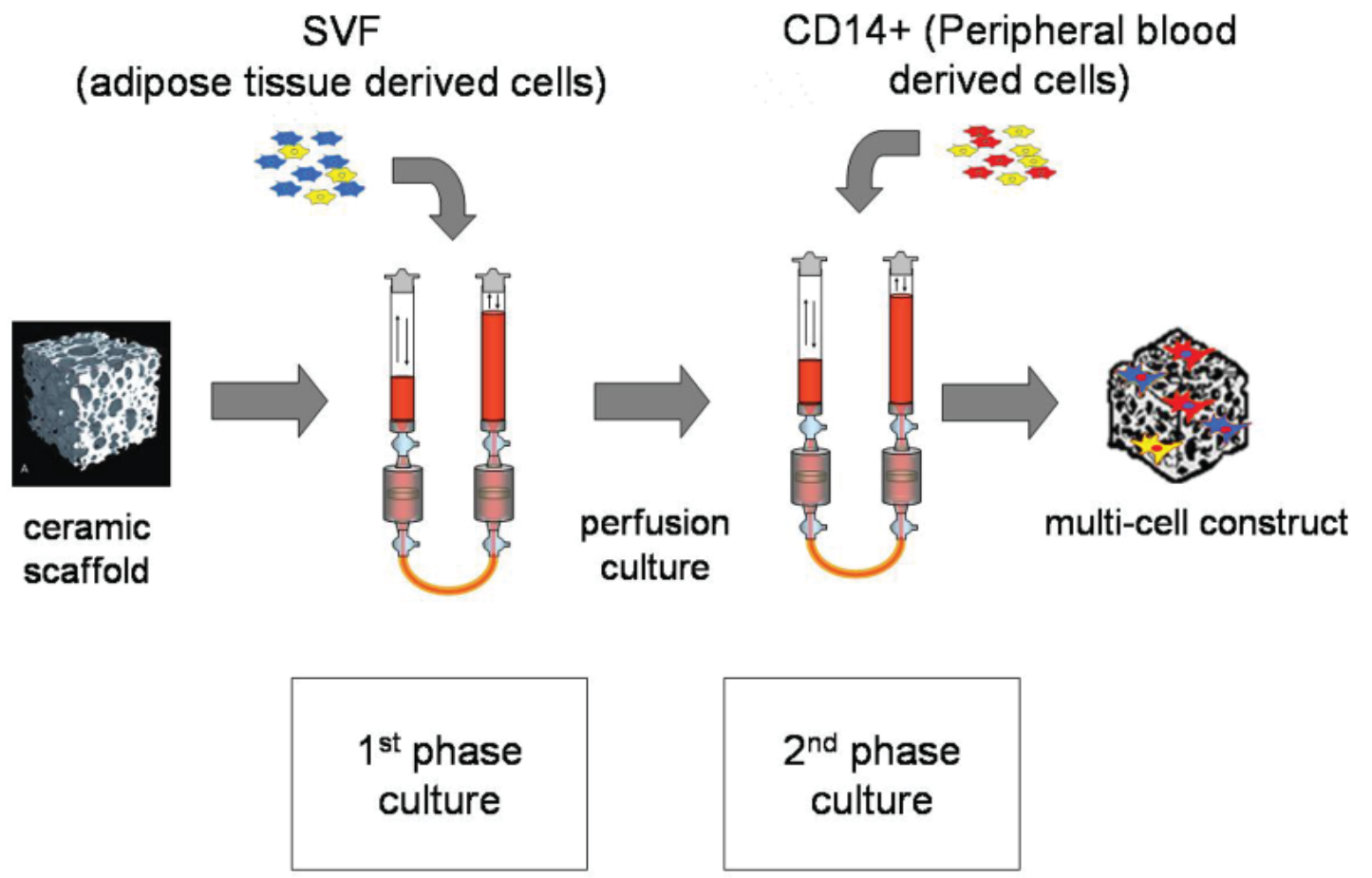

Fig. 1. Schematic representation of the procedure used to generate an osteoblastic-osteoclastic-endothelial lineage cells co-culture model.

cultured to establish baseline levels of soluble factors in the supernatant.

\section{Supernatant analysis}

Prior to each medium refresh, the media were collected, centrifuged at $400 \mathrm{~g}$ for $5 \mathrm{~min}$ and the resulting supernatant stored at $-20{ }^{\circ} \mathrm{C}$. The samples were then thawed and assessed for C-terminus procollagen type I (CICP), crosslinked N-telopeptides of collagen type I (NTx-I, Osteomark ${ }^{\circledR}$ NTx Serum) (both from TecoMedical Group, Sissach, Switzerland), tartrate-resistant acid phosphatase isoform 5b (TRAP5b, BoneTRAP ${ }^{\circledR}$ Immunodiagnostic Systems, Boldon Business Park, UK) and phosphate levels (Biovision Inc, Mountain View, CA, USA). Each assay was performed according to the manufacturers' instructions and each value was subtracted of the corresponding one measured in cell-free scaffolds. For the quantification of phosphate levels, measurements were further normalised by subtracting the levels corresponding to fresh culture medium at each medium change. Positive values corresponded to higher phosphate levels than those in the fresh culture medium in the absence of cells, indicating osteoclastic mediated resorption of the inorganic phase of the extracellular matrix (ECM) and/or of the phosphate phase of the scaffold. Conversely, negative values corresponded to lower phosphate levels than those in the fresh culture medium, indicating phosphate's embedding within the newly deposited ECM.

\section{Scanning electron microscopy (SEM)}

Formalin-fixed constructs, harvested from the perfusion bioreactor system following 21 days of culture, were dehydrated in graded ethanol changes $(30,50,75$, and $100 \%$ ETOH concentration), air dried and sputter coated with $20 \mathrm{~nm}$ of Au (Baltec Med 020, Tucson, AZ, USA). SEM observations were performed with an ESEM XL 30 apparatus (Philips, Eindhoven, The Netherlands) with 10 $\mathrm{kV}$ acceleration.

\section{Cytofluorimetric analysis}

Following 3D cultures, cells were extracted from the ceramic pores by sequentially perfusing a solution of $0.3 \%$ collagenase (for $40 \mathrm{~min}$ ) and $0.05 \%$ trypsin $/ 0.53$ $\mathrm{mM}$ EDTA (for $10 \mathrm{~min}$ ) at the superficial velocity of 400 $\mu \mathrm{m} / \mathrm{s}$. Previous studies using a similar setup indicated that the protocol allows to detach more than $85 \%$ of the total cells in the system (Braccini et al., 2005). The resulting cells were rinsed and incubated in the dark at $4{ }^{\circ} \mathrm{C}$ for 30 min with antibodies against human CD105 (Serotec), CD90, CD34, CD45, CD31, CD14, HLA-A2 (all from BD Biosciences), STRO-1, Alkaline phosphatase (ALP) (both from R\&D Systems), and analysed using a FACSCalibur flow cytometer (BD Biosciences). Positive expression was defined as the level of fluorescence greater than $95 \%$ of the one measured using the corresponding isotype-matched control antibodies.

\section{In vivo analyses}

Constructs generated following 21 days of culture in the perfusion bioreactor system were subcutaneously implanted into dorsal pockets of recipient nude mice (CD-1 nu/nu, 1 month old; Charles River Laboratories, Wilmington, MA, USA), in accordance with institutional guidelines (Kantonales Veterinäramt Basel-Stadt", permission \#1797). Eight weeks after implantation, explants were processed and analysed histologically and immunohistochemically as described below. 


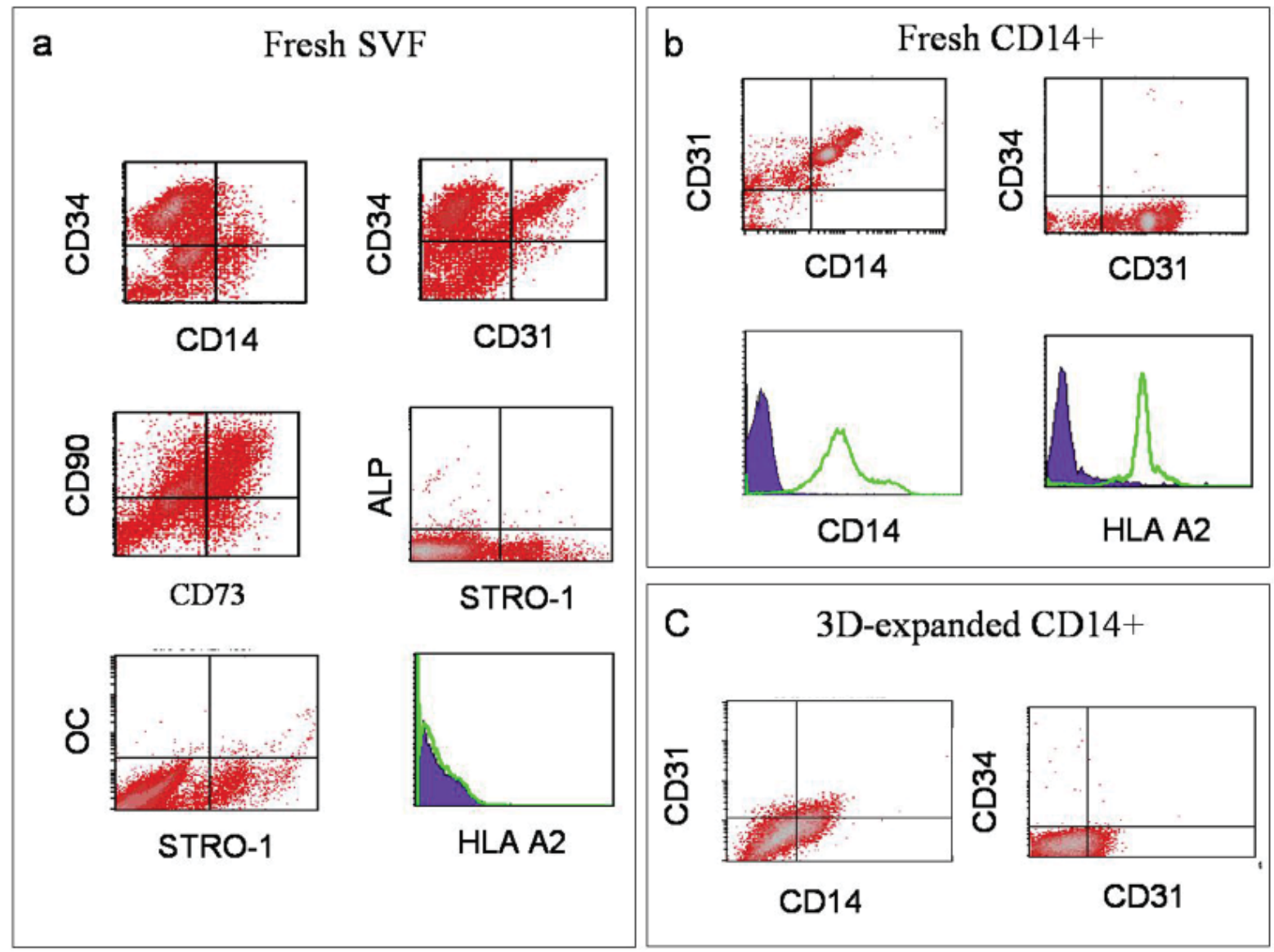

Fig. 2. Representative characterization by means of cytofluorimetry of (a) freshly isolated SVF cells, (b) freshly isolated peripheral blood-derived CD14+ cells and (c) 3D expanded peripheral blood-derived CD14+ cells. Markers used included those typical for osteoclastic (CD14, CD31), stromal/osteoblastic (STRO-1, ALP, OC), endothelial (CD31, CD34) and mesenchymal (CD73, CD90) lineages. SVF and CD14+ cells used in the experiments were selected to be negative and positive for HLA-A2, respectively.

\section{Histological staining and immunohistochemistry}

After in vitro culture or in vivo implantation, constructs were fixed in $1.5 \%$ paraformaldehyde, decalcified with $7 \%$ EDTA solution (Sigma-Aldrich) and embedded in paraffin. Sections ( $5 \mu \mathrm{m}$ thick) were stained for Haematoxylin and Eosin (H\&E) (J.T. Baker/Avantor, Philipsburg, NJ, USA) or for tartrate-resistant acid phosphatase (TRAP) activity using the leukocyte acid phosphatase kit (Sigma-Aldrich). Immunohistochemical analyses were performed to assess the composition of ECM and the human origin of blood vessels or osteoclasts using antibodies against: human collagen type I (Col-I; MPBiomedicals, Solon, OH, USA), human bone sialoprotein (BSP; Enzo Life Sciences, Exeter, U.K.), human CD34 (Chemicon; Millipore, Billerica, MA, USA) and human calcitonin receptor (CTR, Acris Antibodies, Herford, Germany). The immunobinding was detected with biotinylated secondary antibodies and using the appropriate Vectastain ABC kits (Vector Labs, Burlingame, CA, USA). The red signal was developed with the Fast Red kit (Dako Cytomation, Glostrup, Denmark) and sections counterstained by Haematoxylin. Negative controls were performed for each analysis by omitting the primary antibodies. Chromogenic in situ hybridisation (CISH, Zytovision, Bremerhaven, Germany) to detect human Alu repeat sequences was performed as described in the kit. Histological and immunohistochemical sections were analysed using an Olympus BX-61 microscope (Olympus, Tokyo, Japan).

\section{Magnetic resonance imaging (MRI)}

Cultured constructs were placed in Eppendorf tubes (Sarstedt AG, Sevelen, Switzerland) filled with complete medium and assessed by MRI using a 3T Verio whole-body scanner (Siemens Healthcare, Munich, Germany) using a circular-polarised 12-channel receiver head coil. Multicontrast spin echo acquisitions (TR 5000 ms, 32 echoes, $16.1 \mathrm{~ms}$ echo spacing, $0.31 \times 0.31 \mathrm{~mm}^{2}$ in plane resolution, $10 \mathrm{~mm}$ slice thickness) were mono-exponentially fitted (pixelwise) using MatLab R2007b (The MathWorks, Natick, MA, USA) to determine the transverse relaxation time $\mathrm{T}_{2}$.

\section{Statistical analyses}

All values are presented as mean \pm standard deviation. Differences between experimental groups were statistically assessed using Wilcoxon's nonparametric tests. $P<$ 0.05 was considered to indicate statistically significant differences. 


\section{Results}

Establishment of a 3D multi-cell co-culture system In order to generate a 3D co-culture model of osteoblastic, osteoclastic and endothelial lineage cells, progenitors derived from human adipose tissue and peripheral blood were sequentially loaded into porous ceramic-based scaffolds using a perfusion-based bioreactor system, as described in the Materials and Methods section and graphically illustrated in Fig. 1. Freshly isolated cells from human adipose tissue included a highly heterogeneous set of populations, expressing mixed levels of CD14, CD31, CD34, CD73, CD90, STRO-1, alkaline phosphatase (ALP) and osteocalcin (OC), and negative for HLA-A2 (Fig. 2a). CD14+ cells sorted from peripheral blood were predominantly positive for CD31 and HLA-A2, and negative for CD34 (Fig. 2b). After a total of 21 days of 3D co-culture (SVF/CD14+ group), enzymatically retrieved cells included populations of the endothelial $\left(2.0 \pm 0.3 \%\right.$ of $\mathrm{CD} 34^{+} / \mathrm{CD} 31^{+}$cells $)$, pre/osteoclastic (14.0 $\pm 1.4 \%$ of $\mathrm{CD} 14^{+} / \mathrm{CD} 31^{+}$cells) and stromal/osteoblastic lineages (Fig. 3a). The latter cells were at different stages of differentiation according to (Gronthos et al., 1999), with $26.0 \pm 2.8 \%$ STRO- $1^{+} /$ALP- $^{-}$cells (early differentiation) and $18.0 \pm 5.7 \% \mathrm{STRO}^{2} / \mathrm{ALP}^{+}$cells (late differentiation), accounting for a total of $44.0 \pm 8.4 \%$. Following enzymatic treatment, a large density of trypsin-resistant, TRAP ${ }^{+}$ osteoclastic cells were found attached to the pores of the ceramic scaffolds (Fig. 3b). Control constructs seeded with SVF only contained a negligible fraction of pre/osteoclastic lineage cells, a low frequency of osteoblastic committed cells $\left(2.6 \pm 2.2 \% \mathrm{STRO}^{-} / \mathrm{ALP}^{+}\right)$and displayed a TRAP staining pattern close to background levels (Fig. 3a,b). As compared to the SVF/CD14+ co-culture group, SVF-based constructs yielded a lower fraction of stromal progenitor (15.6 $\pm 2.0 \%$ vs. $26 \pm 2.8 \%)$ and CD105+, mesenchymal lineage cells ( $9.8 \pm 2.5 \%$ vs. $24.5 \pm 4.9 \%$ ), while exhibited a higher percent of endothelial lineage cells (10.0 $\pm 1.4 \%$ vs. $2.0 \pm 0.3 \%)$. As expected, the experimental group established using only CD14+ cells did not include $\mathrm{CD} 34^{+} /$ $\mathrm{CD} 1^{+}$endothelial lineage cells and led to a loss of $\mathrm{CD} 14^{+} /$ $\mathrm{CD} 31^{+}$pre/osteoclastic lineage cells during 3D culture (Fig. 2c). Thus, only the SVF/CD14+ experimental group allowed to establish a $3 \mathrm{D}$ co-culture system including osteoblastic, osteoclastic and endothelial lineage cells.

\section{Extracellular matrix (ECM) characterisation in the 3D co-culture model}

We next assessed the ECM developed in the 3D engineered tissue model. Scanning electron microscopy (SEM) qualitatively but reproducibly displayed larger amounts of ECM in the pores of scaffolds seeded with SVF only, as compared to SVF/CD14+ (Fig. 4a, SEM). No traces of ECM were found in samples established using only CD14+ cells, which were comparable to the cell-free scaffold group (data not shown). Quantitative measurements by MRI were consistent with SEM findings. Specifically, the relaxation times $\mathrm{T}_{2}$ for $\mathrm{SVF} / \mathrm{CD} 14+$ samples were similar to those of CD14+ and cell-free samples and higher (i.e., indicating higher water content and lower ECM density) than those

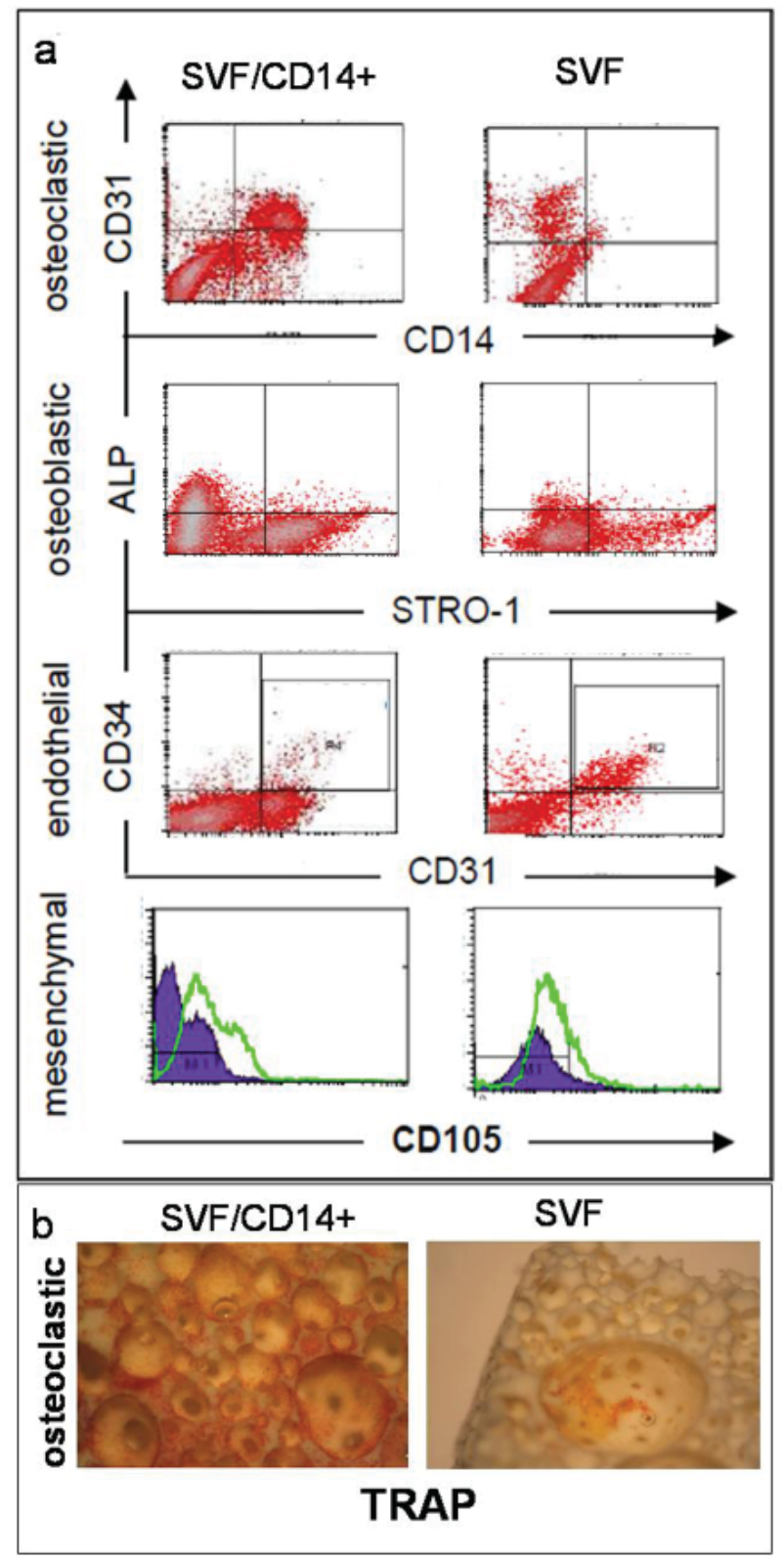

Fig. 3. Representative characterisation of cells extracted from the constructs based on SVF cells or on SVF/ CD14+ co-cultures. (a) cytofluorimetry using typical markers for osteoclastic (CD14, CD31), stromal/ osteoblastic (STRO-1, ALP), endothelial (CD31, CD34) and mesenchymal (CD105) lineage cells. (b) Histochemistry using TRAP stain.

of SVF constructs (Fig. 4b). Histological assessment of the in vitro cultured SVF/CD14+ constructs displayed the presence of TRAP+ osteoclastic cells (Fig. 4a, TRAP) surrounding scattered clusters of ECM intensely stained for Col-I and BSP (Fig. 4a, Col-I \& BSP). In contrast, in SVF constructs, no TRAP+ cells were detected within the abundant ECM positively stained both for Col-I and BSP. The data collectively suggest that the apparent reduction of ECM in the SVF/CD14+ group as compared to the SVF group could be due to the resorption activity by osteoclastic cells. 

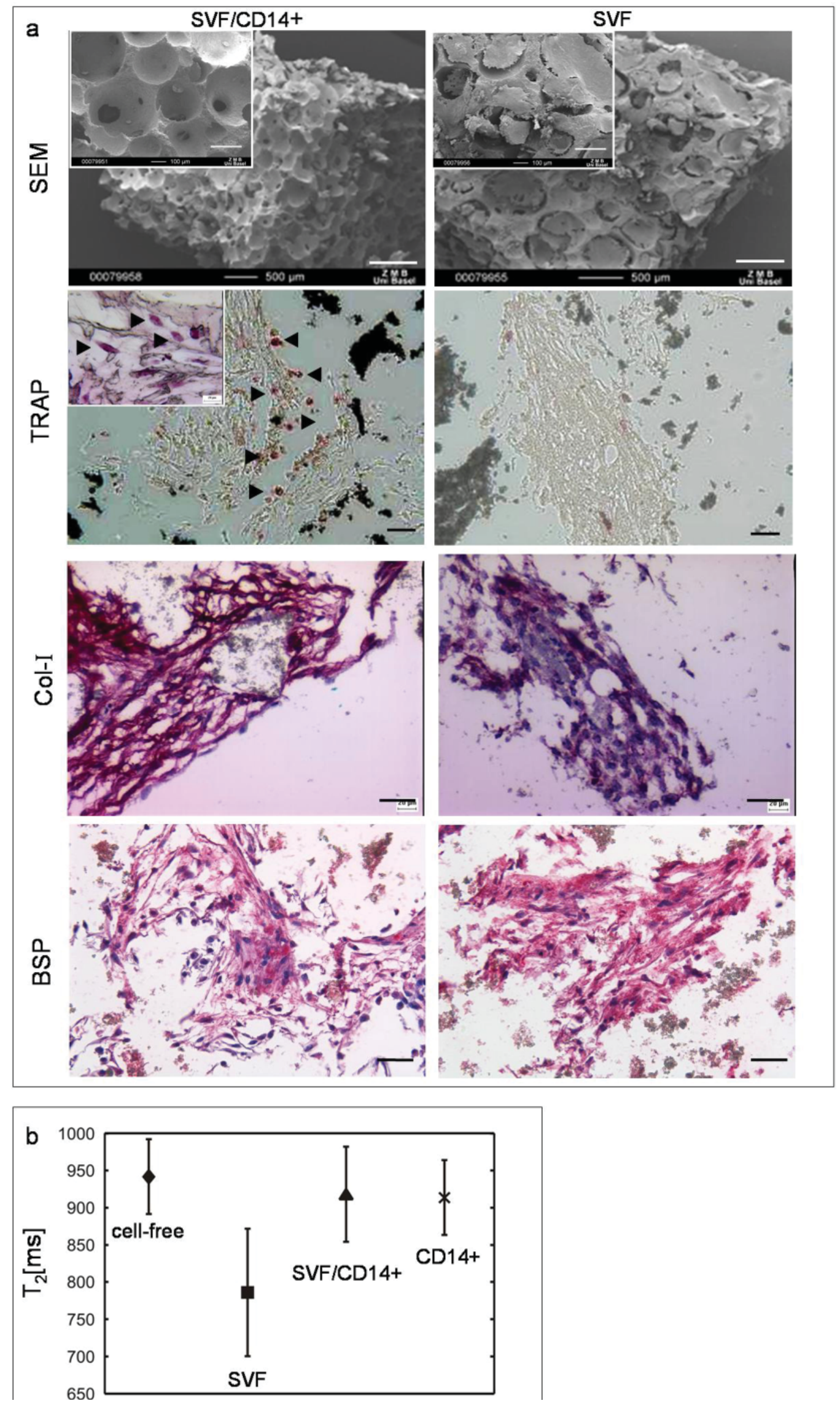

Fig. 4. Representative characterisation of the ECM in the constructs based on SVF cells or on SVF/CD14+ co-cultures. (a) SEM (scale bars $500 \mu \mathrm{m}$, or $200 \mu \mathrm{m}$ in the insets), histochemistry for TRAP (arrowheads indicate TRAP ${ }^{+}$cells, black scale bars $100 \mu \mathrm{m}$, or $40 \mu \mathrm{m}$ in the insets), immunohistochemistry for Col-I (black scale bars $40 \mu \mathrm{m}$ ) and BSP (black scale bars $40 \mu \mathrm{m}$ ). (b) Transverse relaxation time $\mathrm{T}_{2}$ obtained by MRI, including the cell-free and CD14+ control groups. 

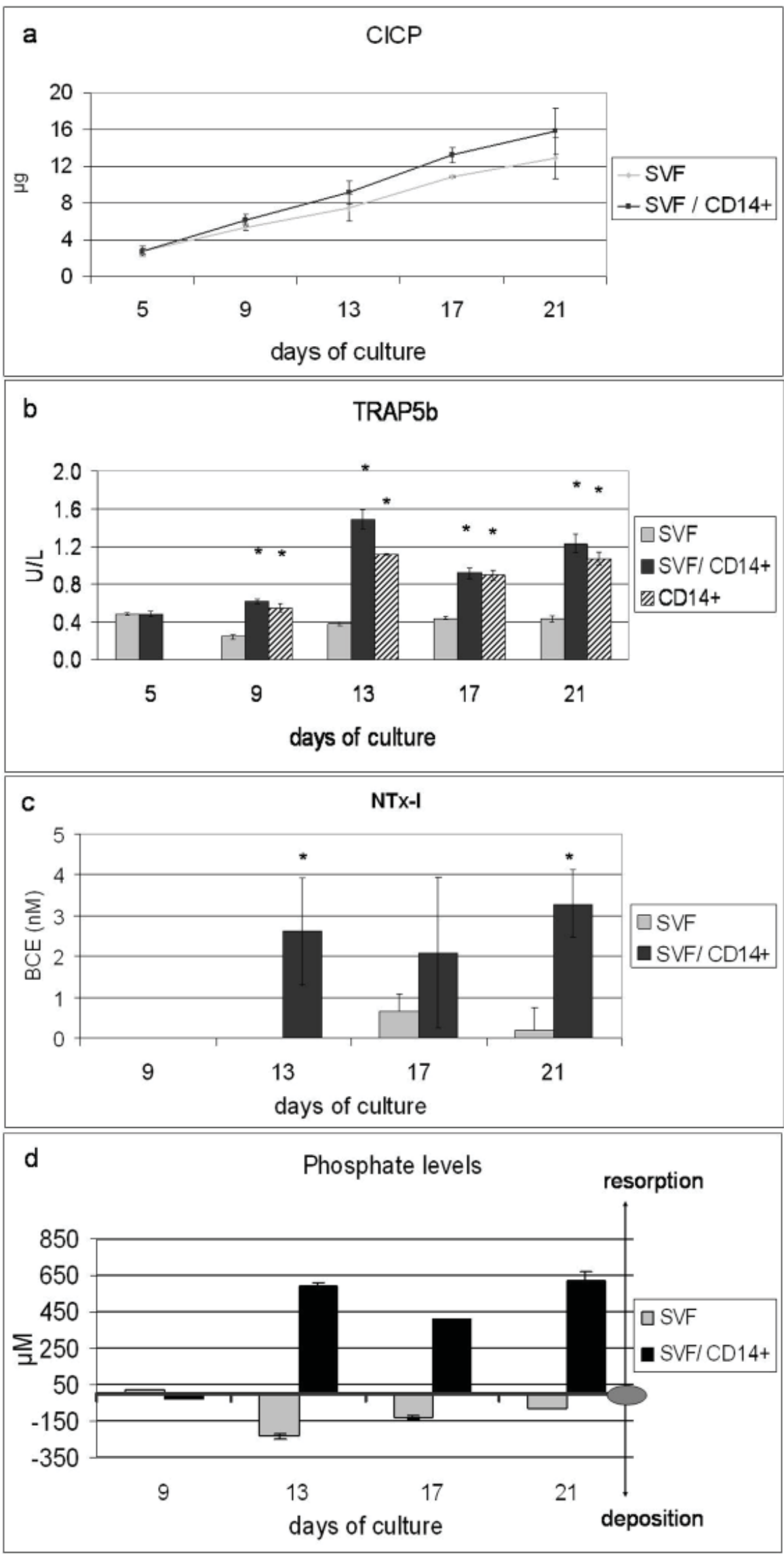

Fig. 5. Non-invasive quantitative assessment of ECM turnover dynamics in constructs based on SVF cells or on $\mathrm{SVF} / \mathrm{CD} 14+$ co-cultures up to 21 days of culture. Culture supernatants were analysed for (a) CICP, indicative of ECM synthesis; (b) TRAP5b, indicative of osteoclastic cell number, including the CD14+ control group; (c) NTX-I, indicative of ECM depsition/resorption; (d) phosphate levels, indicative of ECM deposition/resorption. Asterisks

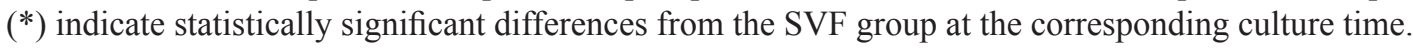



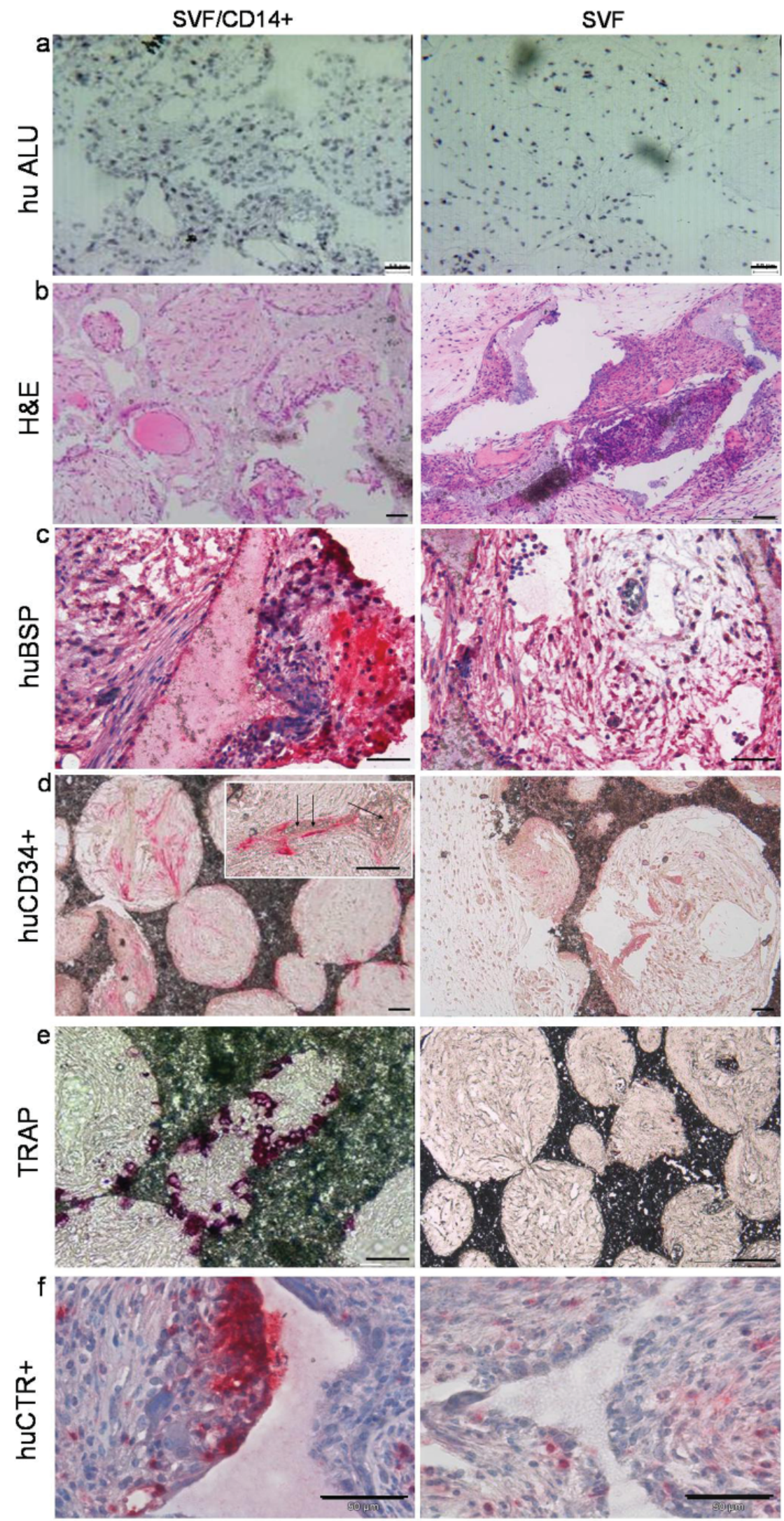

Fig. 6. Histological evaluation of constructs based on SVF cells or on SVF/CD14+ co-cultures after 8 weeks of implantation into an ectopic nude mice model. (a) In situ hybridisation for human-specific ALU sequences; indicative of the presence of human cells; (b) H\&E, indicative of bone-like matrix formation; (c) Immunohistochemistry for human specific BSP, indicative of human derived bone-like matrix composition; (d) Immunohistochemistry for human specific CD34, indicative of blood vessels of human origin (inset: arrows indicate the presence of erythrocytes inside the lumen of blood vessels); (e) Histochemistry for TRAP, indicative of TRAP ${ }^{+}$osteoclastic cells; and (f) Immunohistochemistry for human specific calcitronin receptor (CTR), indicative of mature osteoclasts of human origin. Scale bars $50 \mu \mathrm{m}$, or $40 \mu \mathrm{m}$ in the insets. 

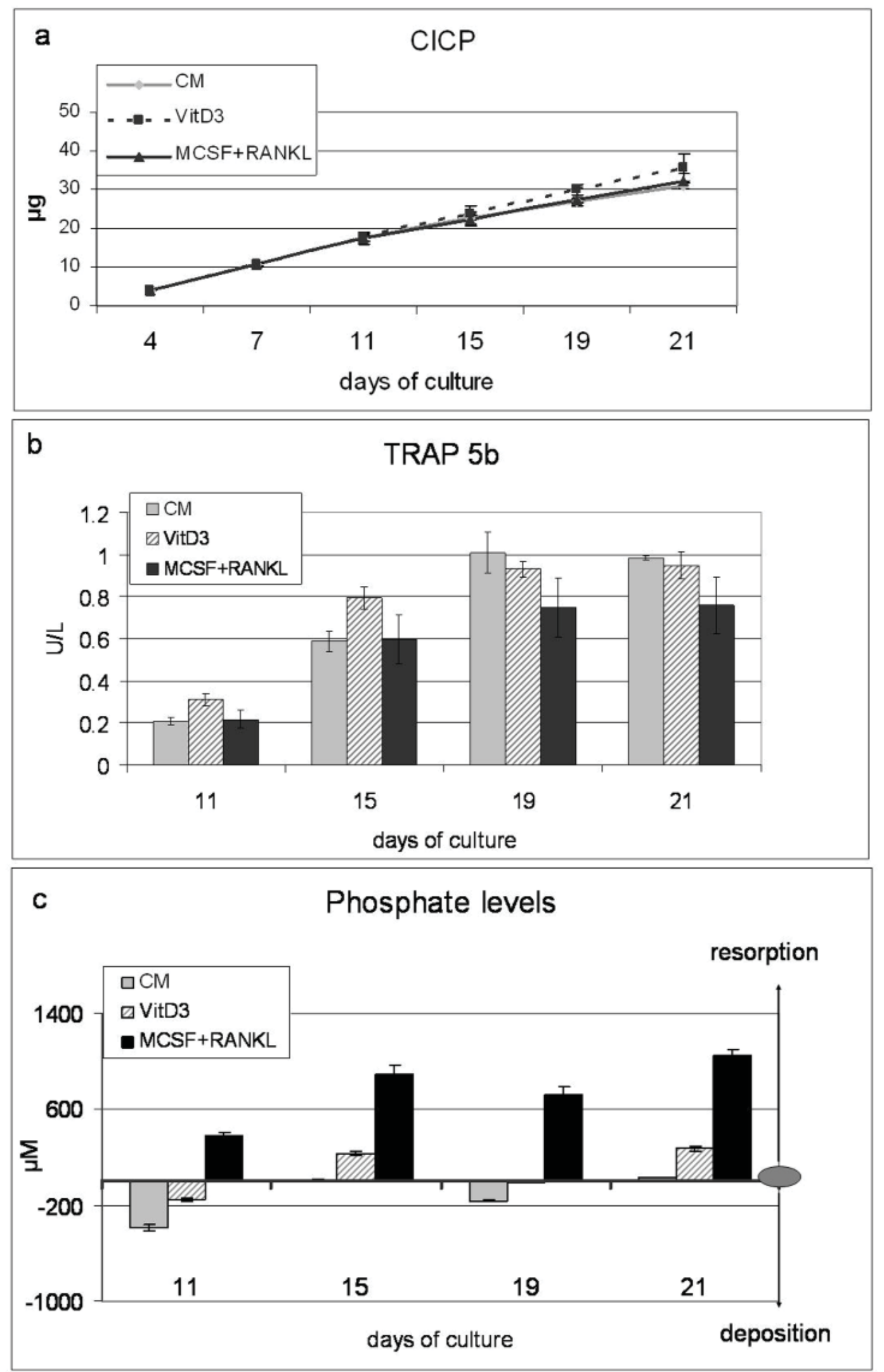

Fig. 7. Non-invasive quantitative assessment of ECM turnover dynamics of constructs based on SVF/CD14+ cocultures in the presence of osteoclastogenic (MCSF\&RANKL), osteotropic ( $\left.\mathrm{VitD}_{3}\right)$ or, in the absence of external soluble factors (complete medium, CM), up to 21 days of culture. Culture supernatants were analysed for (a) CICP, indicative of ECM synthesis; (b) TRAP5b, indicative of osteoclastic cell number; and (c) phosphate levels, indicative of ECM deposition/resorption. 

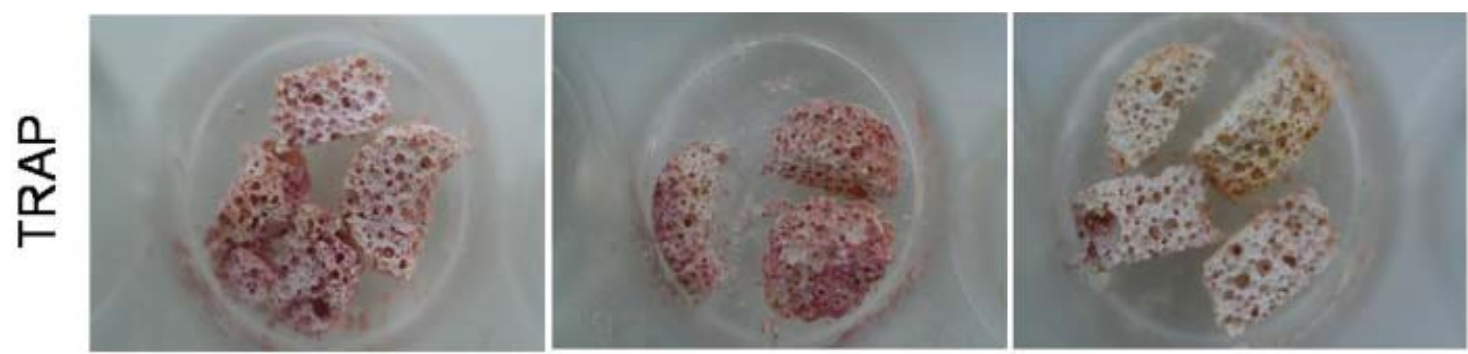

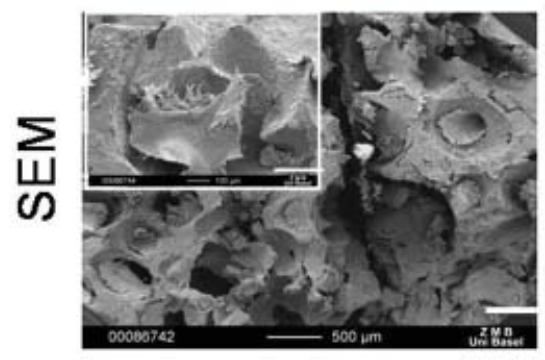

Complete medium

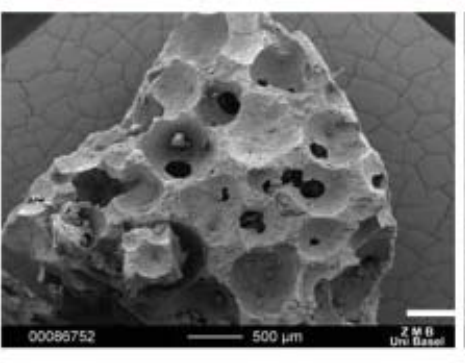

VitD3

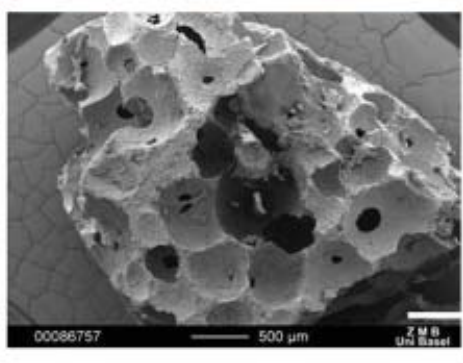

Osteoclastogenic medium

Fig. 8. Qualitative evaluation of ECM of constructs based on SVF/CD14+ co-cultures in the presence of osteoclastogenic (MCSF\&RANKL), osteotropic (VitD3) or in the absence of external soluble factors (complete medium) by means of TRAP and SEM (scale bars $500 \mu \mathrm{m}$, or $200 \mu \mathrm{m}$ in the insets).

\section{Assessment of ECM turnover using non-invasive tools}

In order to non-invasively monitor the process of ECM deposition and resorption over culture time, typical markers of bone remodelling were assessed in the supernatant. Increasing levels of procollagen-I (CICP) were measured in both SVF/CD14+ and SVF conditions (up to $30 \%$ higher in the SVF/CD14+ co-culture group), indicating active and sustained deposition of ECM by mesenchymal/osteoblastic cells (Fig. 5a). Values below the sensitivity of this assay were found for the CD14+ constructs (data not shown). The levels of osteoclast specific isoenzyme TRAP5b were significantly higher (up to 4-fold) in the SVF/CD14+ and CD14+ conditions as compared to the SVF only culture group already from the $2^{\text {nd }}$ medium change, i.e. $4 \mathrm{~d}$ after the fresh CD14+ monocytes were introduced into the culture (Fig. 5b). The levels of NTX-I, indicating osteoclastdriven degradation product of Col-I, were consistently elevated only for SVF/CD14+ samples, whereas the SVF and CD14+ experimental groups displayed significantly lower or undetectable values, respectively (Fig. 5c). Furthermore, positive phosphate values, indicating a net ECM resorption, were found only for SVF/CD14+ samples (Fig. 5d). Phosphate levels were not detected in CD14+ samples and were negative for SVF samples, indicative of a net accumulation of ECM. These data indicate that processes of ECM deposition and resorption are actively ongoing only in the SVF/CD14+ group, likely due to the presence of both osteoblastic and osteoclastic cells.

\section{In vivo performance of the generated $3 D$ constructs}

In order to demonstrate the full functionality of the different cell populations within the $3 \mathrm{D}$ co-culture model, engineered constructs were ectopically implanted in nude mice. After
8 weeks in vivo, explants from both SVF/CD14+ and SVF groups contained a high density of cells of human origin (Fig. 6a), embedded within an ECM including scattered ossicles (Fig. 6b) and structures positively stained for human-specific BSP (Fig. 6c). Blood vessels of human origin, as assessed by positive staining for human CD34, and functionally connected with the host vasculature, as indicated by the presence of erythrocytes, were also found in both conditions (Fig. 5d). TRAP+ and human specific CTR+ multinucleated osteoclasts (Fig. 6e,f) were found only in constructs derived from the SVF/CD14+ co-culture. None of the above described cell types and tissue structures could be observed in the implanted cell-free scaffolds (data not shown). The generally limited amount of bone formation may be related to the culture conditions used, which - in order to promote osteoclast development - may have promoted a predominantly 'catabolic' environment.

\section{In vitro functionality of the 3D co-culture model}

In order to demonstrate a functional coupling of the different cell populations in the SVF/CD14+3D co-culture model, we investigated whether the presence of a well-known osteotropic agent acting on osteoblastic cells (Kitazawa et al., 2003), namely VitD $_{3}$, could indirectly support the formation and activity of osteoclasts. Independently of the culture medium used, the production of procollagen-I (CICP) increased over time, indicating active ECM synthesis (Fig. 7a). Levels of the isoenzyme TRAP5b increased with culture time, indicating an increase in the number of osteoclastic cells, with no substantial differences among the experimental groups (Fig. 7b). Instead, the osteoclastic activity of ECM resorption, assessed by positive phosphate levels in the supernatant, could be demonstrated only in the presence of osteoclastogenic 
factors or of $V_{i t D}$ (Fig. 7c). Constructs treated with VitD displayed initially negative phosphate values, indicative of ECM synthesis, followed by intermittently positive values, indicating a discontinuous ECM resorption process. In line with these results, TRAP+ cells were found in all conditions, whereas abundant ECM filling the scaffold pores was visible by SEM only in control samples, cultured in medium without osteoclastogenic factors or $\mathrm{VitD}_{3}$ (Fig. 8). In order to define the fate of PB-derived monocytes when co-cultured with SVF cells, cytofluorimetry was performed based on HLA-A2 mismatched donors. All conditions exhibited PB-derived cells (HLA-A2 ${ }^{+}$) expressing low frequencies of the mesenchymal marker CD90 (up to $6.9 \%$ ), a fraction of which appeared to co-express the panhematopoietic marker CD45 (up to 2\%) (Table 1). The data suggest a possible mesenchymal conversion of monocytic cells (Kuwana et al., 2003; Kuwana et al., 2006; Yeh et al., 2006) and more generally indicate the potential to track the origin of the cells developed in the co-culture system.

\section{Discussion}

In the present study, we established a 3D osteoblasticosteoclastic-endothelial cell co-culture model, using progenitor cells of human origin derived from easily available sources and a perfusion-based bioreactor device. The developed non-invasive monitoring techniques could quantitatively capture the cell-mediated processes of bone-like matrix deposition and resorption, and validated the cell-based, functional regulation of the system by osteoclastogenic or osteotropic factors.

In order to maintain osteoclastic cells in culture, with a typically short life span, until a bone-like matrix was deposited in the scaffold pores, our model was developed as a two-phase culture system. The $3 \mathrm{D}$ ceramic materials were thus loaded first with freshly harvested SVF cells derived from adipose tissue, initially populating the accessible surface and producing ECM containing BSP and type I collagen. The preformed cell-scaffold constructs were then seeded with peripheral blood derived CD14+ osteoclastic precursor cells. The use of a bioreactor device, directly perfusing the cell suspensions through the construct pores, was instrumental to reproducibly achieve a sequential seeding of the different cell types, likely facilitating heterotypic cell interactions throughout the available spaces. Moreover, the 3D perfusion-based culture regime allowed to expand the cells harvested from the native tissues directly in the scaffolds, bypassing the typical artifactual culture phase in 2D plastic dishes, which is known to affect cell fate (Banfi et al., 2000) and was previously shown to rapidly deplete the endothelial component from human SVF cells (Scherberich et al., 2007). One distinct feature of the developed model was thus the long-term presence in culture of endothelial cells, which are known to modulate the osteoblastic and osteoclastic activity, as well as to regulate the transition from bone matrix resorption to formation (Collin-Osdoby, 1994; Parfitt, 2000).

The main challenge of a 3D culture system is typically
Table 1. Representative characterization of cells extracted from the constructs based on SVF/CD14+ co-cultures in the presence of osteoclastogenic (MCSF\&RANKL), osteotropic (VitD3) or in the absence of external soluble factors (complete medium) using typical markers for mesenchymal (CD90) and pan-hematopoietic (CD45) lineages. SVF and CD14+ cells used in the experiments were selected to be negative and positive for HLA-A2, respectively.

\begin{tabular}{|c|c|c|c|}
\cline { 2 - 4 } \multicolumn{1}{c|}{} & $\begin{array}{c}\text { complete } \\
\text { medium }\end{array}$ & $\begin{array}{c}\text { Osteoclastogenic } \\
\text { medium }\end{array}$ & VitD $_{3}$ \\
\hline CD90(-)/CD45(+) & $1.3 \%$ & $2.4 \%$ & $2.0 \%$ \\
\hline CD90(+)/CD45(+) & $1.0 \%$ & $2.9 \%$ & $2.7 \%$ \\
\hline CD90(+)/CD45(-) & $81.3 \%$ & $88.0 \%$ & $89.0 \%$ \\
\hline & \multicolumn{3}{c|}{} \\
\hline CD45(-)/HLA A2(+) & $3.0 \%$ & $0.8 \%$ & $4.5 \%$ \\
\hline CD45(+)/HLA A2(+) & $2.5 \%$ & $3.2 \%$ & $3.9 \%$ \\
\hline CD45(+)/HLA A2(-) & $0.0 \%$ & $2.0 \%$ & $1.1 \%$ \\
\hline CD90(-)/ HLA A2(+) & $1.0 \%$ & $0.5 \%$ & $1.1 \%$ \\
\hline CD90(+)/ HLA A2(+) & $3.9 \%$ & $3.8 \%$ & $6.9 \%$ \\
\hline CD90(+)/HLA A2(-) & $77.0 \%$ & $86.5 \%$ & $85.0 \%$ \\
\hline $\begin{array}{r}\text { CD90(+)/CD45(+)/ } \\
\text { HLA A2(+) }\end{array}$ & $0.8 \%$ & $1.9 \%$ & $2.0 \%$ \\
\hline
\end{tabular}

related to the inherent difficulty of inspecting the relevant cell processes. In order to address this critical issue, noninvasive techniques were introduced for the qualitative and quantitative monitoring of ECM deposition and resorption. In particular, a set of biochemical markers measured by off-line sampling of the culture medium was established to reflect respectively the deposition of type I collagen, the presence of TRAP5b-secreting osteoclasts and the resorption of mineralised matrix. In addition, measurement of $\mathrm{T}_{2}$ by magnetic resonance imaging (MRI) was shown to correspond to the SEM-detected amounts of extracellular matrix. The use of MRI could be further developed to quantify the amount of specific matrix molecules, for instance by combining it with collagen-specific peptides as contrast agents (Caravan et al., 2007).

The use of the different assays established that the active osteoclastic resorption in this model was dependent on the presence of SVF and their ECM deposition. In fact, collagen degradation products and phosphate levels in the medium were found increased only when monocytic cells were introduced in a SVF pre-seeded construct, where type I collagen was extensively produced. The active resorption process reproduced under these conditions was mirrored by the abundant loss of the SVF-produced ECM, as assessed by SEM. To the best of our knowledge, the developed $3 \mathrm{D}$ co-culture system is thus the first in vitro model that coupled osteoclastic matrix resorption to active matrix deposition by osteoblastic cells.

In the initial configuration, the 3D co-culture model was established by using exogenous growth and differentiating factors known to act directly on osteoclastic precursors (Lacey et al., 1998), and which were permissive in our experimental setup to the induction/maintenance of osteoblastic and endothelial cells. The co-culture of SVF with CD14+ cells resulted in the presence of different osteoblastic cell populations, with an increased percentage of both the more immature $\left(\mathrm{STRO}^{+}, \mathrm{ALP}^{-}\right)$and the more 
differentiated (STRO1-, ALP $^{+}$) phenotypes. On the other hand, besides triggering osteoclasts' resorption activity, the presence of SVF cells contributed to the maintenance of a distinct subpopulation of PB-derived osteoclastic precursors $\left(\mathrm{CD} 14^{+}, \mathrm{CD} 31^{+}\right)$, otherwise lost in the absence of co-culture. Collectively, these results suggest functional interactions among the co-cultured cell types influencing their phenotype.

As a next step, we aimed at demonstrating the in vitro self-regulatory capacity of the developed model, using the paradigm of $\mathrm{VitD}_{3}$-controlled bone resorption (Boyle et al., 2003). In fact, it is known that $\mathrm{VitD}_{3}$ typically induces differentiation of monocyte-macrophages into osteoclasts indirectly, by increasing the RANKL expression by stromal/osteoblastic cells (Takahashi et al., 1988; Yasuda et al., 1998; Kitazawa et al., 2003). In our system, VitD increased collagen production, supported osteoclast formation and triggered osteoclast mediated ECM resorption. Interestingly, analysis of the phosphate values, reflecting the net effect between ECM deposition and resorption, indicated an increased resorption activity in the presence of $\mathrm{VitD}_{3}$, but only at alternate time points. These results may reflect the dynamic nature of ECM turnover in the presence of a factor having both anabolic and catabolic actions on bone (Kitazawa et al., 2003). Investigation of the possible regulation of the transition between these two states as a function of frequency and dose of VitD ${ }_{3}$ supplementation (Miao and Scutt, 2002) was beyond the scope of the present study.

The developed 3D osteoblastic-osteoclastic-endothelial cell co-culture system and the associated analytical tools were able to capture in vitro some aspects of the functional coupling of bone-like matrix deposition and resorption and could thus be used in different contexts. The model may find application in the test of drugs regulating bone homeostasis (Pampaloni et al., 2009) or in the study of biocompatibility/remodelling capacity of bone substitute materials (Kirkpatrick et al., 2007), thus potentially decreasing the use of laboratory animals (Pampaloni et al., 2007). The use of cells of human origin would in this regard support a possibly superior direct relevance in human physiology and pathology. The additional introduction of mechanical loading in the multi-cell model would support investigations of which specific cell population(s) are required in bone as an "organ" to couple biochemical and mechanical signals. By mimicking a bone organ microenvironment, the system could also be used as an engineered 3D niche to study bone-tumour cell interactions, as well as the process of cancer cell metastasis into bone during its turnover (Yin et al., 2005; Hutmacher et al., 2010). Moreover, by presenting both osteoblastic and vascular elements, the 3D environment could be used as an advanced in vitro model to investigate the signals involved in the control of haematopoietic stem cell function (Di Maggio et al., 2011). Last but not least, the developed methods could be exploited toward the engineering of multi-functional bone substitute implants. The intrinsic osteogenic, vasculogenic and remodelling capacity would need to be regulated to reach highly efficient engraftment and performance, whereas the bioreactor-based processes would represent the basis for standardised and costeffective manufacturing (Martin et al., 2010).

\section{Conclusion}

The establishment of a functional in vitro system of osteoblastic, osteoclastic and endothelial lineage cells, along with the associated non-invasive assessments, may find application in a variety of different contexts. These are related to supporting fundamental science of bone biology and translation of the developed knowledge towards bone regeneration

\section{Acknowledgements}

The study was partially funded by the European Space Agency (ERISTO program, No. AO-99-091) and the Swiss National Foundation (No. 310000-120432).

\section{References}

Banfi A, Muraglia A, Dozin B, Mastrogiacomo M, Cancedda R, Quarto R (2000) Proliferation kinetics and differentiation potential of ex vivo expanded human bone marrow stromal cells: Implications for their use in cell therapy. Exp Hematol 28: 707-715.

Boyle WJ, Simonet WS, Lacey DL (2003) Osteoclast differentiation and activation. Nature 423: 337-342.

Braccini A, Wendt D, Jaquiery C, Jakob M, Heberer M, Kenins L, Wodnar-Filipowicz A, Quarto R, Martin I (2005) Three-dimensional perfusion culture of human bone marrow cells and generation of osteoinductive grafts. Stem Cells 23: 1066-1072.

Caravan P, Das B, Dumas S, Epstein FH, Helm PA, Jacques V, Koerner S, Kolodziej A, Shen L, Sun WC, Zhang Z (2007) Collagen-targeted MRI contrast agent for molecular imaging of fibrosis. Angew Chem Int Ed Engl 46: 8171-8173.

Collin-Osdoby P (1994) Role of vascular endothelial cells in bone biology. J Cell Biochem 55: 304-309.

David V, Guignandon A, Martin A, Malaval L, LafageProust MH, Rattner A, Mann V, Noble B, Jones DB, Vico L (2008) Ex Vivo bone formation in bovine trabecular bone cultured in a dynamic 3D bioreactor is enhanced by compressive mechanical strain. Tissue Eng Part A 14: 117-126.

Detsch R, Mayr H, Ziegler G (2008) Formation of osteoclast-like cells on HA and TCP ceramics. Acta Biomater 4: 139-148.

Di Maggio MN, Piccinini E, Jaworski M, Trumpp A, Wendt DJ, Martin I (2011) Toward modeling the bone marrow niche using scaffold-based 3D culture systems. Biomaterials 32: 321-329.

Domaschke H, Gelinsky M, Burmeister B, Fleig R, Hanke T, Reinstorf A, Pompe W, Rosen-Wolff A (2006) In vitro ossification and remodeling of mineralized collagen I scaffolds. Tissue Eng 12: 949-958. 
Gronthos S, Zannettino AC, Graves SE, Ohta S, Hay SJ, Simmons PJ (1999) Differential cell surface expression of the STRO-1 and alkaline phosphatase antigens on discrete developmental stages in primary cultures of human bone cells. J Bone Miner Res 14: 47-56.

Hauge EM, Qvesel D, Eriksen EF, Mosekilde L, Melsen F (2001) Cancellous bone remodeling occurs in specialized compartments lined by cells expressing osteoblastic markers. J Bone Miner Res 16: 1575-1582.

Heinemann C, Heinemann S, Worch H, Hanke T (2011) Development of an osteoblast/osteoclast co-culture derived by human bone marrow stromal cells and human monocytes for biomaterials testing. Eur Cell Mater 21: 80-93.

Hutmacher DW, Loessner D, Rizzi S, Kaplan DL, Mooney DJ, Clements JA (2010) Can tissue engineering concepts advance tumor biology research? Trends Biotechnol 28: 125-133.

Kirkpatrick CJ, Fuchs S, Hermanns MI, Peters K, Brochhausen C, Unger RE (2007) Cell culture models of higher complexity in tissue engineering and regenerative medicine. Biomaterials 34: 5193-5198.

Kitazawa S, Kajimoto K, Kondo T, Kitazawa R (2003) Vitamin D3 supports osteoclastogenesis via functional vitamin D response element of human RANKL gene promoter. J Cell Biochem 89: 771-777.

Komano Y, Nanki T, Hayashida K, Taniguchi K, Miyasaka N (2006) Identification of a human peripheral blood monocyte subset that differentiates into osteoclasts. Arthritis Res Ther 8: R152.

Komlev VS, Mastrogiacomo M, Pereira RC, Peyrin F, Rustichelli F, Cancedda R (2010) Biodegradation of porous calcium phosphate scaffolds in an ectopic bone formation model studied by X-ray computed microtomograph. Eur Cell Mater 19: 136-146.

Kuwana M, Okazaki Y, Kodama H, Izumi K, Yasuoka H, Ogawa Y, Kawakami Y, Ikeda Y (2003) Human circulating CD14+ monocytes as a source of progenitors that exhibit mesenchymal cell differentiation. J Leukoc Biol 74: 833-845.

Kuwana M, Okazaki Y, Kodama H, Satoh T, Kawakami Y, Ikeda Y (2006) Endothelial differentiation potential of human monocyte-derived multipotential cells. Stem Cells 24: 2733-2743.

Lacey DL, Timms E, Tan HL, Kelley MJ, Dunstan CR, Burgess T, Elliott R, Colombero A, Elliott G, Scully S, Hsu H, Sullivan J, Hawkins N, Davy E, Capparelli C, Eli A, Qian YX, Kaufman S, Sarosi I, Shalhoub V, Senaldi G, Guo J, Delaney J, Boyle WJ (1998) Osteoprotegerin ligand is a cytokine that regulates osteoclast differentiation and activation. Cell 93: 165-176.

Martin I, Riboldi SA, Jakob M, Wendt D (2010) SnapShot: Bioreactors systems in tissue engineering (TE) $\&$ regenerative medicine (RM). Biomaterials 31: 31143115.

Matsuo K, Irie N (2008) Osteoclast-osteoblast communication. Arch Biochem Biophys 473: 201-209.

Meghji S, Hill PA, Harris M (1997) Bone organ cultures. In. UK: Chapman and Hall, 106-126.

Miao D, Scutt A(2002) Recruitment, augmentation and apoptosis of rat osteoclasts in 1,25-(OH)2D3 response to short-term treatment with 1,25-dihydroxyvitamin D3 in vivo. BMC Musculoskelet Disord 3: 16.

Nakagawa K, Abukawa H, Shin MY, Terai H, Troulis MJ, Vacanti JP (2004) Osteoclastogenesis on tissueengineered bone. Tissue Eng 10: 93-100.

Pampaloni F, Reynaud EG, Stelzer EH (2007) The third dimension bridges the gap between cell culture and live tissue. Nat Rev Mol Cell Biol 8: 839-845.

Pampaloni F, Stelzer EH, Masotti A (2009) Threedimensional tissue models for drug discovery and toxicology. Recent Pat Biotechnol 3: 103-117.

Parfitt AM (1994) Osteonal and hemi-osteonal remodeling: the spatial and temporal framework for signal traffic in adult human bone. J Cell Biochem 55: 273-286.

Parfitt AM (2000) The mechanism of coupling: a role for the vasculature. Bone 26: 319-323.

Pearce AI, Richards RG, Milz S, Schneider E, Pearce SG (2007) Animal models for implant biomaterial research in bone: a review. Eur Cell Mater 13: 1-10.

Pogoda P, Priemel M, Rueger JM, Amling M (2005) Bone remodeling: new aspects of a key process that controls skeletal maintenance and repair. Osteoporos Int 16 Suppl 2: S18-S24.

Scherberich A, Galli R, Jaquiery C, Farhadi J, Martin I (2007) Three-dimensional perfusion culture of human adipose tissue-derived endothelial and osteoblastic progenitors generates osteogenic constructs with intrinsic vascularization capacity. Stem Cells 25: 1823-1829.

Simpson AE, Stoddart MJ, Davies CM, Jahn K, Furlong PI, Gasser JA, Jones DB, Noble BS, Richards RG (2009) TGFbeta3 and loading increases osteocyte survival in human cancellous bone cultured ex vivo. Cell Biochem Funct 27: 23-29.

Sorensen MG, Henriksen K, Schaller S, Henriksen DB, Nielsen FC, Dziegiel MH, Karsdal MA (2007) Characterization of osteoclasts derived from CD14+ monocytes isolated from peripheral blood. J Bone Miner Metab 25: 36-45.

Takahashi N, Yamana H, Yoshiki S, Roodman GD, Mundy GR, Jones SJ, Boyde A, Suda T (1988) Osteoclastlike cell formation and its regulation by osteotropic hormones in mouse bone marrow cultures. Endocrinology 122: $1373-1382$.

Tortelli F, Cancedda R (2009) Three-dimensional cultures of osteogenic and chondrogenic cells: a tissue engineering approach to mimic bone and cartilage in vitro. Eur Cell Mater 17: 1-14.

Tortelli F, Pujic N, Liu Y, Laroche N, Vico L, Cancedda $\mathrm{R}$ (2009) Osteoblast and osteoclast differentiation in an in vitro three-dimensional model of bone. Tissue Eng Part A 15: 2373-2383.

Wendt D, Marsano A, Jakob M, Heberer M, Martin I (2003) Oscillating perfusion of cell suspensions through three-dimensional scaffolds enhances cell seeding efficiency and uniformity. Biotechnol Bioeng 84: 205-214.

Yamada S, Heymann D, Bouler JM, Daculsi G (1997) Osteoclastic resorption of biphasic calcium phosphate ceramic in vitro. J Biomed Mater Res 37: 346-352.

Yasuda H, Shima N, Nakagawa N, Yamaguchi K, Kinosaki M, Mochizuki S, Tomoyasu A, Yano K, Goto M, Murakami A, Tsuda E, Morinaga T, Higashio K, Udagawa 
N, Takahashi N, Suda T (1998) Osteoclast differentiation factor is a ligand for osteoprotegerin/osteoclastogenesisinhibitory factor and is identical to TRANCE/RANKL. Proc Natl Acad Sci USA 95: 3597-3602.

Yeh SP, Chang JG, Lo WJ, Liaw YC, Lin CL, Lee CC, Chiu CF (2006) Induction of CD45 expression on bone marrow-derived mesenchymal stem cells. Leukemia 20: 894-896

Yin JJ, Pollock CB, Kelly K (2005) Mechanisms of cancer metastasis to the bone. Cell Res 15: 57-62.

Zaidi M, Alam AS, Bax BE, Shankar VS, Bax CM, Gill JS, Pazianas M, Huang CL, Sahinoglu T, Moonga BS (1993) Role of the endothelial cell in osteoclast control: new perspectives. Bone 14: 97-102.

\section{Discussion with Reviewers}

Reviewer II: This is an interesting culture model with many potential uses. So far it has been taken out to $21 \mathrm{~d}$, how long do you think it would be possible to culture the cells for? Authors: In previous studies we have demonstrated that the perfusion-based 3D culture system allows to uniformly maintain living cells within porous scaffolds for at least 6 weeks, even after the initially open spaces have been progressively filled with extracellular matrix. In the co-culture model presented in this manuscript, however, an extended duration of the culture period may be compromised by the relatively short lifespan of mature osteoclasts. It is reasonable that these cells may not be replaced by fresh ones due to the only initial availability of osteoclast progenitors in the system.

Reviewer III: The interpretation of the results is a little bit complicated since the authors solely use indirect detection methods (measured in the supernatant, without cell lysis). Please substantiate why these "non-invasive" methods are representative for the examined processes in their opinion. Aurhors: The results obtained with the "non-invasive" techniques have been confirmed to be representative of the examined processes using typical destructive methods such as Cytofluorimetry, SEM, histology and immunohistochemistry. The use of alternative techniques, including PCR analyses, could be additionally tested. However, results would likely be biased by the presence of variable fractions of different cell types, which would challenge a correct normalisation of the measured transcripts.

Reviewer III: It is unusual to measure phosphate levels in the supernatant in order to determine resorption/deposition processes since the phosphate level is influenced by numerous factors - not necessarily related with the cellular resorption of a substrate. Please explain why they decided to use the phosphate level (instead of calcium etc.) for resorption analysis and why these results are believed to be representative for the whole cell-material-interaction. Authors: It is known that calcium and phosphate precipitate in bone matrix as hydroxyapatite crystals. Therefore it is a reasonable choice to look for both elements when bone turnover process is examined. We agree also with the reviewer that the levels of calcium and phosphate are influenced by various factors not only related to cellmediated deposition and resorption of a given substrate. Moreover, significant levels of these elements can be found in the media used for cultures (alpha-MEM, bovine serum) but also due to random dissolution of mineral components derived from the ceramic scaffolds, which may lead to erroneous values. Taking into account the aforementioned factors, we performed several control experiments (e.g. cell-free, single cell-type cultures, fresh medium) to establish baseline levels of soluble factors in the supernatant. In our work we have also evaluated calcium measurements (using Calcium colorimetric assay kit K380-250, Biovision, data not shown). However, in contrast to phosphate measurements, the baseline levels derived from controls were high and the differences calculated from the tested experimental groups turned out to be below the sensitivity range of this assay $(<0.1$ $\mathrm{mM}$ ) and therefore not reliable. In conclusion, we agree that phosphate measurements cannot be used alone to represent the cell-ECM-material interaction and should be considered together with other bio-markers or assessments (e.g., the ones reported in the manuscript) for a proper evaluation of the examined processes. 